\title{
NOTAS ACERCA DE LA MORALIDAD DE LA ACCIÓN ${ }^{1}$
}

\author{
Humberto Giannini \\ Con la colaboración de \\ Eva Hamamé \\ Universidad Diego Portales \\ y Juan José Fuentes \\ Universidad de Chile \\ gianninluz@mi.cl
}

\begin{abstract}
Resumen
Nuestro texto no trata el tema lógico-lingüístico de las proposiciones, sino el tema ético de la comunicación humana. Comunicar es vincularse a otro ser humano mediante alguna referencia al mundo. A la ética importa describir y clasificar las diversas especies que se crean a través de la acción comunicativa y sus posibles transgresiones. Tema importante para comprender por qué toda acción humana -pero, en especial, la acción comunicativaes éticamente evaluable, es el estudio que aquí se hace del concepto aristotélico-tomista de 'circunstancia'.

PALABRAS CLAVE: experiencia moral, acción, significado, sentido, circunstancia.

Abstract

Our text is not about the logical-linguistic issue proposais, but rather about the ethical issue of human communication. To communicative is to link to another human being using some reference to the world. Ethics is concerned with describing and classifying every single kind of links that are created by communicative action and its possible transgressions. An important issue to understand why every single human action -but specially, communicative action-is subject of ethical evaluation, is the study we do here about the Thomist-Aristothelic concept for 'circumstance'.
\end{abstract}

KEY WORDS: moral experience, action, significance, sense, meaning, circumstance.

Agradezco la valiosa participación en este escrito de mis colaboradores Eva Hamamé (Universidad Diego Portales) y Juan José Fuentes (Universidad de Chile) que forman parte de mi equipo de investigación. 


\title{
I. De la acción en general
}

"En el principio era la acción"

Goethe, Fausto

\begin{abstract}
RT 1. Es especialmente a propósito del desear, que puede hacerse visible la discontinuidad insalvable -el 'salto'- que existe entre la subjetividad del acto resolutivo y la acción por la que ese deseo intenta satisfacerse en el mundo ${ }^{2}$. Esto, porque en la acción, 'el motor' se manifiesta -y a él se le percibe cuando actúa-no solo como portador de un movimiento, sino como agente en virtud del cual tal movimiento se inicia y se dirige hacia algún punto. Por tanto, como sujeto al que se le atribuye la autoría ${ }^{3}$ ya no de un mero movimiento sino de una acción que tiene efectos inmediatos en el espacio natural y en el mundo humano. La acción inaugura una realidad nueva sin precedentes ni en la consciencia ni en el deseo; algo nuevo en la propia biografía y algo nuevo también en el acontecer del mundo. Pero detengámonos ante una consecuencia epistemológica notable que sigue a la comprobación de este rasgo doblemente inaugural: que toda acción es el inicio contingente de una historia que, sin embargo, pende con necesidad de tal inicio. Este hecho paradójico hizo decir a Giambattista Vico que cualquier acción es un pequeño mito, y a Paul Ricoeur, en nuestros tiempos, que el modo propio de comprender una acción concreta es la narración.
\end{abstract}

2. A partir de esto, volvamos, ahora, al punto en el que una resolución subjetiva se vuelve acción en el mundo. Actuar es estar ya más allá de la mera resolución subjetiva y, no obstante, hablar todavía en el lenguaje de la subjetividad, sin mostrar qué es lo que hacemos en el mundo cuando actuamos en él. Actuamos, sí, ¿Pero qué hacemos cuando actuamos? Por eso, habría que agregar ahora que la actualidad propia del actuar es el realizar-hacer real-algo ${ }^{4}$.

-¿Qué haces?

- 'Rompo con mis propias manos el contrato'.

Es el hacer (agere) el que revela el significado ${ }^{5}$ la intervención concreta del sujeto como actor en el mundo. A este desenlace de la acción -a lo que se hace cuando se actúa- lo llamaremos 'significado'.

Lo que el psicoanálisis ha llamado, desde Freud, 'satisfacción real'.

Se le imputa.

Producir desde sí un hecho, un efecto (ex factum), no un objeto (ob-iectum).

Nos parece interesante mostrar un ejemplo de acción comunicativa sin palabras que da Ricoeur: [“¿Qué haces?] "Extiendo el brazo para indicar que doblaré a la izquierda”. (Ricoeur 
Ahora, si nos mantenemos fieles a la idea de que el sujeto actuante, incluso poseedor del saber más elemental que cabría imaginar, 'sabe' al actuar qué es lo que ahora está haciendo, vemos que el concepto de significado se vuelve inmediatamente aplicable a las acciones en general y, especialmente, a cualquier acción comunicativa real. Pues en la acción comunicativa se juega antes que una modificación del mundo un modo de ser-con-otro, o mejor, de vincularse a otro. Lo que está haciendo un sujeto respecto de otro es comunicarle un significado, pro-ponerle un modo de ser.

Convengamos, por ahora, que el ser de la acción, su eidos, es el significado. Una acción que no poseyera significado no sería acción, sino un movimiento mecánico o una convulsión orgánica que se explica por causas externas. Una acción se realiza como significado porque confirma el ser y la identidad de quien la realiza y porque revela algo de ese ser a otro sujeto, que la percibe y la juzga.

Es posible, sin embargo, que un sujeto no logre realizar el significado de la acción que se propone: que quiera saltar a un bote y, malogrando su intento, caiga en medio del agua o que el individuo, a quien dirige su S.O.S. no alcance a escucharlo y se quede con la palabra en la boca. O, por último, que un actor (teatral) no logre imitar el sentimiento que pretende evocar con su actuación ${ }^{6}$. Una acción es praxis y no teoría; y una acción comunicativa es doblemente praxis, pues está dirigida a vincularse a otro sujeto, y a través de este último, al mundo. Por tanto, debe ser evaluada en conformidad al grado de éxito o cumplimiento que obtiene el agente en el acto de significar ${ }^{7}$ algo para otro. Pero éste es solo un punto de la cuestión.

Ahora bien, a propósito de la diferencia esencial entre acto y acción (en sentido genérico), vimos que en virtud de esta última el sujeto remueve o promueve, directa o indirectamente, algo en el mundo (Agit ad extra $)^{8}$. Podemos agregar, entonces, que si al acto se le llama 'intencional', de la acción puede decirse que es 'intencionada'9 en cuanto la experimentamos e interpretamos como un movimiento hacia un fin ${ }^{10}$, es decir, 'en vistas de' algo en virtud de lo cual el movimiento se realiza y se plasma como

1963, pp. 13-30). Lo que hago -al extender mi brazo- es ya una acción comunicativa: indicar la próxima dirección de mi ruta.

Malogros, infortunios en lo que se intenta hacer.

Si digo 'te prometo', y el destinatario entiende lo que digo, solo por este hecho he tenido éxito en el significado. Y no por el hecho empírico de cumplir mi promesa después.

8 Directamente, en el hacer algo: en la artesanía, por ejemplo; indirectamente, en la acción comunicativa. Por ejemplo: En la acción de ordenar cerrar una puerta produzco un cambio físico, siempre y cuando el sujeto que recibe la orden, la ejecute.

9 Y que a veces la enjuiciamos como 'malintencionada'.

10 No nos referimos al fin último que postula la tradición aristotélico-tomista, sino al propósito inmediato o 'a la vista' de la acción. A la animalidad, en general, podría negársele la comprensión de la finalidad de lo que hace. Negarle, en cambio, cierta comprensión del fin inmediato que lo lleva al objeto es una postura bastante infundada. 
acción. A este destino de la acción le llamaremos 'sentido'. Y demos por establecido también que un movimiento no intencionado no es acción ${ }^{11}$.

3. 'Sentido' es la finalidad que se propone un sujeto al hacer algo. De otra manera: es la pre-visión de la próxima acción en vistas de la que alguien hace lo que ahora está haciendo. Cabe que tal finalidad sea simplemente la realización y continuidad de lo que se hace de modo consabido o con ritmo circadiano en vistas del más elemental cuidado de nuestro propio ser. O bien, que la finalidad se agote en eso mismo que está haciendo: si alguien está jugando ping-pong no tiene sentido (común) preguntarnos por el sentido de lo que hace. O si alguien ayuda a levantarse del suelo a aquel que se ha caído, tampoco tiene sentido (común) preguntarle por el sentido ${ }^{12}$ de su acción. Simplemente, hay acciones que no se hacen en vista o en función de otra cosa, sino que 'valen', que se justifican por ellas mismas.

Adelantemos algo sobre las acciones comunicativas. También éstas se especifican por su significado; por ejemplo, la pregunta ‘¿Qué haces?’ es evidentemente una acción interrogativa, y el destinatario responderá ${ }^{13}$-si es que responde verbalmente- de cierta manera, especificando su acción: por ejemplo:'Escribo a tu hermano'.

Estamos todavía en el ámbito del significado, en el ámbito de preguntar algo, de responder algo o bien no responder más que con el silencio. Es el campo de la exposición abierta, eidética, al otro. Queda todavía por examinar el ámbito más oculto: ‘¿Por qué escribe a mi hermano?' El ámbito del sentido. Preguntarse por el sentido de lo que se habla corresponde a una tarea más compleja y, sin embargo, esencial. Descuidada en general por la tradición filosófica.

¿En vistas de qué hablamos?

Incluso la pregunta, a este nivel, parece ociosa: se habla para vincularse de un modo determinado a otro sujeto, con el fin de 'hacerle ver algo' ${ }^{14}$. La dificultad reside aquí en acotar en una sola definición el 'para qué', respuesta que va a depender siempre de la situación concreta en la que los sujetos se encuentran, de la relación que mantienen, de lo que está aconteciendo entre ellos, etc. Y justamente, el sin sentido de la acción aparece cuando lo que se dice 'no viene al caso', cuando al parecer se habla por hablar o por exteriorización patológica de un discurso autista.

En toda comunicación real hay un sujeto que actualmente se dirige a otro sujeto, a fin de mostrarle algo (real, posible o meramente imaginario). Este es el sentido

11 Recordemos que los 'actos fallidos' de Freud son expresión de intenciones reprimidas que se realizan a pesar de la determinación represora de la conciencia.

12 En otros escritos nos hemos referido a la categoría esencial del sentido común. Cf., Giannini, H., La Metafísica eres Tú, cap. V.

13 Si es que la escucha.

14 Hacerle ver, es decir, que comprenda, que atienda a..., etc. 
inmediato, incuestionable, que supone toda comunicación: dirigir la palabra a otro sujeto con algún propósito vinculante.

El problema vuelve a complicarse cuando el sentido de lo que alguien hace es diverso de, o adverso a lo que el destinatario puede esperar del significado de la acción. Cuando tratemos más estrictamente acerca de las acciones comunicativas comprobaremos que el sentido de una acción adquiere en este punto, justamente por su posibilidad esencial de ocultamiento, un peso cuya importancia solo podemos ahora insinuar.

En pocas palabras, comunicarse es vincularse a otro sujeto en el modo en que lo declara, explícita o implícitamente, el significado de la acción, es decir, mostrando, pidiendo, exigiendo, prometiendo... algo. Ahora, el sentido que posee tal acción (su 'en vistas de qué'), en la mayor parte de los casos se infiere del mismo significado o de la situación común que están experimentando aquellos que ahora se comunican. Entre el significado de la acción y su sentido hay un lazo empírico consabido, en línea de máxima, por los actuantes e imposible de codificar teóricamente: ¿¿Por qué me prometes?' - 'Porque quiero asegurarme que me creas'...- 'Porque quiero asegurarme que haré lo que digo', 'Porque quiero obtener ahora algo de ti', y así, ad infinitum.

Es una propiedad esencial de la acción comunicativa que el vínculo que alguien se pro-pone establecer, actuando, pueda servir para ocultar al receptor lo que realmente piensa y quiera hacer el agente. Que, como el demonio castelliano (Castelli 1952, p. $15)$ - se muestre para ocultar ${ }^{15}$. Dicho brevemente: la expresión puede convertirse en un modo insuperable de 'prestidigitación' en el que el mismo prestidigitador se oculta justamente a través de lo que muestra.

De ahí, entonces, que el espacio público sea también el lugar propicio de la sospecha, de la suspicacia y más, en general, del incurable estado de interpretación respecto del actuar ajeno; un ejercicio diario de hermenéutica avant la lettre. Un ejercicio de casuística, también.

Para concluir este punto: Significado y sentido son dos momentos esenciales de la vinculación que se pro-pone ${ }^{16}$ al destinatario de una comunicación concreta. Y en el clima público de la sospecha ambiente siempre es posible preguntarnos qué vinculación se me está proponiendo y con qué intención, no puesta sobre la mesa. Pues mientras que por el significado de la acción se me puede estar mostrando algo positivo, por ejemplo, el ofrecimiento a mi ciudad de un hermoso caballo de madera, el sentido de este don, en cambio, puede envolver el desastre para quienes lo reciben.

Empleando las categorías clásicas de análisis: una acción puede ser esencial, específicamente, positiva: regalar algo, por ejemplo. En cambio, puede ser mala, dañina, insidiosa, por alguna circunstancia, tal vez por algún 'ardid' que no pertenece al ser específico o al menos, consabido de la acción.

15 Las ideologías, por ejemplo.

16 Pro-ponemos: ponemos 'ante los ojos', por así decir. 
Como vemos, el sentido, esto es, hacia dónde se encamina la intención supuestamente oculta de quien actúa ante otro, representa una circunstancia capaz de invertir los valores y tornar, entonces, lo que es bueno por principio, en malo de hecho ${ }^{17}$.

4. La tradición no separaba, por lo general, el movimiento animado (el 'desde-sí') del movimiento hacia un fin en vistas del cual se mueve el cuerpo animal. Lo concebía como un impulso indescomponible. Algo semejante sigue ocurriendo en la comprensión corriente de la acción: para esta comprensión resulta absolutamente ininteligible una acción que no albergue un $\mathrm{fin}^{18}$ inmediato o relativamente mediato. Un 'motivo' en vistas del cual el movimiento se puede llamar intencionado o sensato ${ }^{19}$. Y que, entonces, pueda comprenderse.

Andrés Gide imaginó, en una de sus novelas (Gide 1914), la comisión de un crimen que debía ser perfecto, esto es, insoluble justamente por carecer de motivación, por representar en el proyecto del asesino 'una acción absolutamente gratuita'. Lo que no habría considerado Gide es que el ideal del crimen perfecto es él mismo imperfecto, por cuanto la falta de motivación se convierte en motivación, en la finalidad del crimen, y un detective más perspicaz que el asesino pudo también haber cogido la última trama de sentido de la acción: su gratuidad.

¿Qué queremos decir? Que parece seguir siendo válida la intuición primitiva por la que cualquier móvil animado se mueve 'desde sí en vistas de algo'. Y a este 'en vistas de algo' es lo que llamaremos 'sentido' o motivo, para seguir trabajando con un lenguaje más cercano al movimiento que a la intencionalidad.

Esto nos permite concluir ahora que narración ${ }^{20}$, significado y sentido constituyen los caracteres por los que se nos hace inteligible y sensato el movimiento humano. Caracteres siempre inestables e inciertos para un observador externo, pues, si bien el significado puede hacérsenos patente ${ }^{21}$ en la mayoría de las circunstancias y situaciones

17 Volveremos sobre esto.

18 Incluimos la acción que posee un fin en sí misma: $V$. gr., tocar la guitarra, hablar sánscrito, contemplar una puesta de sol.

19 Así como una proposición tiene sentido gramatical cuando cumple con condiciones sintácticas y léxicas determinadas, así se dice que una acción tiene sentido común cuando alguien la cumple en el lugar, modo, tiempo, etc., debidos.

20 La narración hace comprensible una acción en sus orígenes, no en sus causas.

21 Se comprende que no siempre es así: "El mismo gesto de alzar el brazo, en la serie de cuadros de Giotto que se encuentra en la Cappella Arena de Padua, significa sucesivamente el bautismo en el Jordán, el milagro de Caná, la expulsión de los mercaderes del templo, el saludo a la ciudad de Jerusalén, etc. La acción de alzar el brazo es cada vez interpretada en relación a contextos diferentes." (Ricoeur 1986, p. 55). Queda pendiente saber si el significado de la acción es más patente por lo que expresa el sujeto actuante (v. gr., 'Yo prometo x') o por lo que expresa su cuerpo significante (mirada, ademanes, firmeza de la voz, etc.) En todo caso, es casi inconcebible la pasividad marmórea del cuerpo. La acción es corp-oral a tal punto que la expresión oral del significado puede quedar, y queda casi 
en que nos encontramos con otros sujetos en el espacio civil, el sentido, en cambio, escapa por principio a una aprehensión 'objetiva'. Es más bien a propósito del sentido, del doble sentido y de la mala intención que se supone en el actuar ajeno, que la hermenéutica, antes de ser un método científico, pertenece a la práctica cotidiana, de la cual raras veces suele salvarse el actuar ajeno.

5. Por último, así como narratividad, significado y sentido nos llevan a la 'inteligibilidad' de la acción, es preciso empezar a referirnos a una cuarta característica que, de otra manera que las anteriores, es inseparable de todo actuar. Se trata de los valores de 'bueno' y 'malo', que en la tradición se extendían a todo lo que es.

\section{Lo bueno y lo malo en las acciones}

"La descripción de la acción es la base sobre la cual la ética puede ser construida"

P. Ricoeur, La semantique de la action

1. Ahora bien, en una actitud teórica, contemplativa, las cosas del mundo son descritas como objetos subsistentes, simplemente dados a la representación individual. En otra disposición anímica, esos mismos objetos u otros pueden revelársenos como programables y útiles a nuestros planes y proyectos individuales o colectivos. En el primer caso, los valores de 'bueno' o 'malo' no parecen pertinentes a la cosa descrita; en el segundo, la cosa, en cuanto utilizable, se dice 'buena' si llega a hacer lo que se espera que haga ${ }^{22}$. Y este es el caso del artefacto construido para el servicio, así como el del ente enderezado a un fin, natural o artificial, o bien el caso del ser humano, en cuanto se le percibe, define y valora por su rendimiento en la obra. O por último, el mismo saber teórico, puesto al servicio de la técnica, la economía o el poder.

Sin embargo, no por haber perdido su conexión con una metafísica del bien final $^{23}$-es decir, del Bien-, los términos de 'bueno' y 'malo' han dejado de tener plena vigencia como expresiones que poseen significado y sentido para calificar los objetos de nuestra experiencia ${ }^{24}$. Siendo así, ¿qué es lo que queremos decir hoy cuando afirmamos

siempre, implícita (por ejemplo, cuando negamos algo a alguien solo con un movimiento de cabeza).

22 En el caso de la Providencia -'Y Dios vio que era bueno' (Gén, I)- este ver que confirma a Dios la bondad de su obra, hace del concepto cristiano de 'bueno' un concepto trascendental (aplicable a todo lo creado); y hace de Dios el Bien mismo.

23 La filosofía aristotélico-tomista del fin último.

24 'Bueno' y 'malo', bajo esta concepción utilitarista y pragmática siguen siendo, en cierto sentido, trascendentales o más bien, pseudo-trascendentales pues son también términos co-extensivos a todo lo que es. 
que un ente es bueno? Cosa extraña: nuestro modo actual de entender el término, si lo limitamos a la experiencia 'secular' que tenemos de las cosas, calza perfectamente con la definición formal de la tradición -al menos en principio: Una cosa se dice 'buena' en referencia a una operación suya en virtud de la cual elaboramos otra $\cos ^{25}$ cuya realidad o realización nos importa.

Algo muy distinto a cuando afirmamos que algo es bello, por ejemplo, puesto que la belleza parece inherente a la cosa bella -por decirlo así: emana de ella. En cambio, la pregunta por el ser bueno de la cosa abre a una nueva pregunta: ¿buena para qué? o ¿en relación con qué fin?

Hay que convenir, entonces, en que no existe la cosa buena en sí; que un ente es bueno en virtud y solo en virtud de una operación suya, la cual, aislada o requerida por quien se sirve de ella, permite a éste alcanzar un determinado fin o colabora en su $\operatorname{logro}^{26}$. A la cosa se la llama 'buena' en cuanto relato del fin, de su correlato.

Hoy todo el mundo sabe lo que se quiere decir con el término 'bueno': de un cuchillo, de un reloj, etc., se dice que son buenos cuando hacen aquello para lo cual fueron construidos o han sido destinados: cortar, para el cuchillo, dar la hora a la hora, para el reloj; para el operario y para el funcionario, poner en movimiento las máquinas e instrumentos en función de la tarea proyectada por el agente primero del proyecto.

En conclusión: 'bueno', en este uso pseudo-trascendental que tiene, no describe algo así como una cualidad intrínseca de la cosa sino una relación, esto es, el nombre que se le da a una cosa, $v$. gr., a un negocio, solo por relacionarse de cierta manera con otra cosa, v. gr., con las utilidades que da (Aristóteles 1988, 6b27). Y entonces, desde la perspectiva del sujeto proyectante, no solo la operación será buena o mala, sino la cosa operante, en relación con el logro o malogro del fin que se ha propuesto al emplearla.

Ahora, si es cierto que un ente es bueno en la medida en que obra conforme a un fin determinado, sin embargo, no cabe decir que tal cumplimiento sea bueno para el instrumento, ni directamente bueno para quien lo pone en marcha, sino para el sujeto que ha planificado la obra para algo que él considera bueno: el fin. Y toda acción es (o parece ser) buena para un individuo sensato que la pone en acto $^{27}$.

Sin embargo, en ninguna de estas acepciones, ‘bueno’ y ‘malo’ tienen directamente que ver con algún tipo de preocupación moral. Respecto de la pregunta técnica, utilitaria, las acciones por medio de las cuales llega a ser buena la vida misma quedan fuera de foco; y sobre todo queda fuera el Bien que hace buena esa vida. Pregunta ardua esta

25 Tomás de Aquino, refiriéndose a los trascendentales: "Hay algunas cosas que agregan algo a la comprensión del ente en cuanto expresan un modo del mismo que no se expresa con el nombre de ente" (De Aquino 1996, art. I, in corp). Ahora bien, uno de estos modos “(...) expresa la conveniencia (convenientia) de un ente con otro (...) La conveniencia del ente con el apetito se expresa con el nombre de "bueno" (De Aquino 1996, art. I, in corp).

26 Decimos 'co-laborar', en cuanto siempre es requerida la acción del operario o del agente.

27 Esto es lo que en páginas anteriores hemos llamado ‘sentido’ de la acción. 
pregunta por el Bien, si insistimos en concebirla aristotélicamente (Aristóteles 1988, 1094a20), esto es, como la pregunta por aquello que ya no se hace solo para lograr otra cosa, y luego, otra y otra, indefinidamente (Aristóteles, 1988: 1094a24), sino como aquel fin final por el que se realiza humanamente la existencia del sujeto humano.

Es justamente acerca de ese Bien, que hoy es difícil pronunciarse sin acudir a la metafísica tradicional de la Causa incausada o a la fe religiosa en el regreso del alma al seno de la divinidad.

2. Hemos partido aquí del concepto de movimiento, aplicado a la acción. En términos genéricos, la acción es movimiento y alteración locales. Y esta acción podemos describirla precisamente como un movimiento, en este caso, 'desde sí' (el ekousion aristotélico) o ‘espontáneo' (el von Selbst kantiano).

Pero resulta incomprensible un movimiento 'desde sí' que no implique con necesidad un ir hacia... un moverse 'en vistas de'... o para algo. En caso contrario, ¿cómo podría ser 'desde sí'?

Para responder a esta cuestión nos hemos referido al significado: qué es lo que se hace al actuar; y al sentido: el en vistas de qué, o para qué, como connotaciones esenciales e inseparables de una acción.

Esta descripción sería válida, según Aristóteles (Aristóteles 1988, 111b6), tanto para los niños como para los animales superiores. Para el filósofo griego, la acción propiamente humana va acompañada, además, de razón y, en el mejor de los casos, es dirigida por ella.

Y en este punto se abriría la distancia que tenemos respecto a Aristóteles. Nuestro punto de partida es la experiencia moral en cuanto experiencia del otro. En este sentido, la experiencia que tenemos tanto de la vida animada como de un movimiento hacia lo otro en vistas de sí no describe el hecho originario de la experiencia que nosotros pretendemos destacar: experiencia por la que un desde-sí se mueve hacia otro desdesí para vincularse a él ${ }^{28}$ de cierta manera. Una experiencia que describe más que un cierre sobre sí mismo ${ }^{29}$, una experiencia originaria de autolimitación, ya ética. Digamos por ahora que este vincularse al otro, en cuanto otro sujeto, es el punto originario y distintivo de la acción comunicativa y, al mismo tiempo, de toda moral posible, en el plano de la convivencia humana.

El 'traspaso de mundo', con todos los conflictos y acuerdos cotidianos que supone, es el hecho radical de la historia. Y es a través de tales conflictos y acuerdos que se vienen decantando y delimitando los significados específicos de las acciones por las que nos vinculamos inmediatamente a los otros $\mathrm{y}$, mediatamente, a un mundo común.

28 Experiencia en que el vincularse de cierta manera es la acción comunicativa.

29 Como podría entenderse la famosa descripción de Heidegger en Ser y Tiempo: 'el ser humano es aquel que va delante de sí en vistas de sí mismo.' 
Consideramos, por tanto, que el significado específico de las acciones comunicativas es un criterio ineliminable en la investigación acerca de la experiencia moral.

En la comunicación cotidiana con los otros creemos saber que algunas determinadas acciones son 'buenas' en cuanto promueven la comunicación entre los individuos; y que algunas son 'malas' en cuanto la dificultan, la mediatizan o la destruyen. La larga experiencia histórica de la interacción ha venido sedimentando, especificando el significado de unas y otras como modos de tender una vinculación a otro sujeto. Así, es posible juzgar una acción no desde una teoría abstracta del Bien último sino en virtud de su significado, compartido por una comunidad lingüística y espiritual.

Digamos por el momento que todas las acciones que son 'malas' violentan y destruyen la comunicación, que es condición del Bien común de la humanidad. Entonces, tales acciones son evaluadas negativamente a causa de su propio significado específico; otras, en cambio, son evaluadas positivamente, a causa de lo mismo.

Queda, sin embargo, un amplio campo de acciones que por su significado son indiferentes a una evaluación moral: cantar, caminar por la playa, regalar algo, etc.

Cabe, como veremos más adelante, que una acción sea específicamente buena o indiferente desde el punto de vista moral, y que, sin embargo, cambie radicalmente el valor específico que tiene, en razón de alguna circunstancia.

Y esto es lo que ahora quisiéramos destacar: que debido a las circunstancias, el campo de la experiencia moral y de la 'hermenéutica' que ella alimenta se extiende a la totalidad del universo de las acciones.

3. Hemos fijado antes la experiencia moral, esto es, la experiencia del otro, como nuestro punto de partida y de llegada; y hacíamos hincapié en que esta experiencia no puede ser sino comunicativa.

Ahora deberemos abordar el tema de la acción comunicativa e investigar el sentido moral que pueden tener allí los valores de 'bueno' y 'malo', teniendo a la vista esta nueva categoría de las circunstancias, que aquí hace verdaderos estragos.

Pero, antes, es preciso que determinemos esta categoría de circunstancia en cualquier acción.

\section{Las circunstancias}

1. Hemos insistido en que el significado es el eidos de la acción humana: el 'qué es' (quid) aquello que el sujeto hace específicamente cuando actúa. Sin embargo, definir la acción no es todavía dar cuenta de todo lo que hace el actor; pues, la especificación de lo que hace no da cuenta de la condición sui géneris del movimiento desde sí del actor, movimiento que además de un punto de arranque supone un 'dirigirse hacia...', y en vistas de algo que está al alcance inmediato o mediato de ese iniciativa. Pues, 
¿Cómo podríamos llamar 'movimiento desde sí' a uno que no tiene su destinación prevista desde el inicio? Y ¿cómo podríamos llamar inicio a lo que no prevé algún fin?

Con todo, la intencionalidad concreta del actor es externa al significado, una contingencia en relación con él, así como -nos recordará Tomás de Aquino- el color negro es algo externo y separable respecto a la condición específica de animal racional del ser humano. Y, no obstante, no hay individuo humano que no posea color (o tamaño, o forma, etc.). En resumen: el 'para qué', el sentido de la acción que se hace -esencial en la comprensión de la biografía del actor y de la valoración concreta de sus acciones- pertenece a otro género que el del significado de la acción; es más, es variable y contingente respecto a él ${ }^{30}$.

El estudio de la acción nos instala en un territorio en el que la valoración de lo bueno y lo malo va a depender en todos los casos del modo en que una acción se vincula a la vida de otros sujetos, ya sea por su significado específico o por otras razones, como es el sentido (intencionalidad) de su acción, entre otras. Considerando que un sujeto, en cuanto actúa, no está en general forzado por otra cosa externa a hacer lo que hace, que entonces actúa desde-sí, se dice que su acción le es imputable; esto es, que el sujeto es causa de la acción que afecta a otros sujetos, para bien o para mal ${ }^{31}$.

2. A partir de estos rasgos propios de la acción, repetiremos ahora la pregunta: ¿Cuándo es éticamente evaluable una acción, en general?

En primer término, examinaremos la pregunta desde la perspectiva de su significado específico. A través de los siglos, la interacción humana ha venido identificando ciertas acciones por las que se vinculan con mutuo provecho los miembros de esa comunidad, y las distingue de aquellas acciones nocivas a su comunión. Es el caso de los hábitos que conforman las virtudes éticas examinadas por Aristóteles (Aristóteles 1988, 11131114b25). O el caso de las acciones que justamente por su significado promueven la discordia y la incomunicación, como los vicios capitales, examinados en el Medioevo (Cf., Casiano, 1965).

No obstante, aunque una acción sea buena por su significado específico, puede ser enjuiciada como mala por el sentido que se supone mueve a su ejecutor concreto. Y nunca faltarán argumentos, con justeza o sin ella, para sospechar que el agente se ha movido por intenciones que invalidan ${ }^{32}$ el significado expresado por su acción

30 Este sería un caso de 'metábasis allo genos' (una transgresión de género).

31 Que significado específico y sentido sean ambas condiciones inseparables de la acción puede ya advertirse en el hecho de que quien extravía el sentido de su acción -quien llega a no saber para qué hace algo (excluimos de esto a la acción que no se hace por otra cosa: que es fin en sí misma)- por este mismo hecho deja que se le escape de las manos la iniciativa, y lo que hace se vuelve ajeno e insignificante.

32 Le quitan su dignidad, su estima, podríamos decir, en la medida en que traicionan o rompen con la fidelidad o sinceridad expresada en ese significado hasta allí compartido, frustrándose la reciprocidad. 
comunicativa; para sospechar que lo que testimonia el hablante por el hecho de dirigirse a mí, sirva para ocultarme, por decirlo así, el verdadero sentido de su acción, es decir, sirva para excluirme del mismo vínculo que se me está ofreciendo.

De esta manera, todo el campo valorativo marcado por la ética tradicional (virtudes y vicios) en función de su significado específico puede ser drásticamente contrariado por la sospecha de que el sentido oculto de lo que se hace sea éticamente incompatible con el testimonio del significado ${ }^{33}$. Tal sospecha fue el motor de la hermenéutica (post freudiana, post-marxiana, post-nietzscheana...) que penetrara profusamente la mentalidad del siglo pasado.

El sentido es un factor individualizante; una de las instancias en que ocurre toda acción concreta y que puede invalidar o alterar drásticamente su valor o su mera neutralidad moral.

3. Teóricamente, esta comprobación posee una importancia esencial por cuanto permite radicar con fundamento la investigación ética en la acción, más propiamente en la interacción humana. Y no solo en razón de sus significados específicos sino a propósito del concreto encontrarse de los seres humanos en situaciones y circunstancias que van a determinar su valor moral, su imputabilidad o su no imputabilidad, especialmente cuando se trata de acciones que acarrean daño a otro sujeto.

Es justamente a propósito de las situaciones particulares que el Estagirita examina las acciones que, ocurriendo por ignorancia de algún factor contingente, de lo circunstancial (perístasis) y justamente a causa de tal factor, llevan a un resultado no previsto por el agente. ¿Son imputables o no lo son? (Cf., Aristóteles 1988, 1110b30).

En la Ética a Nicómaco (Aristóteles 1988, 1110b18-1111a22) hay un claro reconocimiento de la no-imputabilidad, cuando un sujeto, conociendo el significado específico de su acción (y sus consecuencias habituales), al realizarla, no prevé, sin embargo, alguna eventualidad que viene a alterar el resultado esperado por el mismo agente, y daña a otro sujeto. A esta eventualidad la denomina 'circunstancia'. Pero no se detiene a examinarla sino que se conforma con enumerar sus modos: "tal vez no esté de más precisar cuáles y cuántas son. Y tienen que ver con quién actúa, qué hace, el ámbito en que actúa, y a veces el medio con que actúa (con qué instrumento), para qué y el modo (dulcemente, con fuerza)" (Aristóteles 1988, 1111a15).

Adelantemos que para nosotros el 'para qué, el sentido, representa 'un elemento esencial' y dialécticamente determinante para la vigencia o no vigencia de los significados, en el enjuiciamiento de todos los días, y no es nunca una mera contingencia más de la acción. 
Volviendo al pensamiento de Aristóteles: si el sujeto agente ignora la circunstancia, este tipo de ignorancia eximirá de culpabilidad al agente, siempre que se cumplan dos condiciones en esta no-imputabilidad:

a) Que no haya ninguna razón ligada al significado específico de la acción que autorice prever la ocurrencia de la eventualidad que lo afecta, v. gr., un temporal, desatado extrañamente en pleno verano, que impida concurrir a una cita.

b) Pero tal tipo de contrariedad excusa siempre y cuando la circunstancia sea insuperable y motivo de un sincero sentimiento de pesar para el agente. En caso contrario, la eventualidad sería una suerte de cómplice gratuito de la verdadera expectativa de quien actúa.

Todo esto viene a confirmar que, para el filósofo griego, en la acción no basta saber lo que se hace sino, además, consentir a eso mismo que se hace o, en todo caso, preferirlo (proairesis) frente a algo que se presenta como alternativa obligada ${ }^{34}$.

El concepto de circunstancia no vuelve a aparecer en la obra de Aristóteles, salvo una vez. En Tomás de Aquino va a tener, en cambio, una importancia esencial para establecer de un modo definitivo que cualquier acción es evaluable desde un punto de vista moral.

Para el aquinatense, tanto el vicio como la virtud ${ }^{35}$ entran en el mundo por la acción y al menos en este punto no agrega nada nuevo respecto al pensamiento de Aristóteles. La novedad va a residir, sin embargo, en la extensión que adquirirá la cuestión de la imputabilidad moral para el filósofo cristiano, y por la misma razón, su ampliación en los dominios y en la especificación de la ética respecto de todas las demás ciencias. El concepto que permitirá tal extensión es justamente el concepto de circunstancia (perístasis), tratado solo de paso por el Estagirita en Ética, como hemos dicho, y solo nombrado en la Metafísica (Cf., Aristóteles 1990, 1013a33).

Es cierto, reconoce Tomás de Aquino, que atendiendo a su significado (species) hay acciones que por ese mismo significado, son buenas $-v$. gr., hablar con veracidad, ser generoso; otras, que en virtud de éste son malas, como engañar.

En el art. V de la Quaestio II del De Malo, Tomás de Aquino se pregunta si es que hay algunas acciones que, siendo indiferentes por su significado (ni buenas ni malas), sean susceptibles de un enjuiciamiento moral (negativo). Y responde que sí, y que lo son en razón de las circunstancias ${ }^{36}$. Nos parece conveniente reproducir la fundamentación que el teólogo da en esta Quaestio:

34 El ejemplo del naufragio ofrecido por Aristóteles en Ética a Nicómaco, 1988, 1110a7.

35 Para Aristóteles, tanto vicio como virtud son modos de habitar el mundo, es decir, hábitos, que se aprenden a partir de la reiteración de ciertas acciones.

36 Citamos solo por curiosidad: Refiriéndose al vicio de la gula, Tomás de Aquino recuerda un verso mnemotécnico que ilustra sus circunstancias posibles, en este caso agravantes: 
"Hay que decir, así como se ha dicho antes, que la acción moral, además de la bondad y la maldad que tiene por su especie [significado], puede tener otra bondad u otra maldad por las circunstancias, las que se relacionan a la acción moral así como los accidentes [se relacionan a la sustancia primera]. Y así como al género se le considera en su definición sin diferencias (sin las que no podría ser especie), así a la especie se la considera según su definición sin accidentes (accidentes sin los cuales no podría ser individuo). En efecto de la definición de hombre no se sigue que sea blanco o negro o algo de este tipo. Luego, al hablar de las acciones morales, en cuanto se las considera en su significado [específico], pueden decirse buenas o malas por el género; pero la bondad o maldad que es por las circunstancias no conviene a ella según su género o su especie; con todo, tal bondad o tal maldad puede convenir a los actos individuales.

Luego, si hablamos de la acción moral según su especie, entonces no toda acción moral es buena o mala, pues hay algunas que son indiferentes, por cuanto, como ya se dijo, la acción moral tiene la especie por el objeto en concordancia con su definición. Y hay objetos que producen algo conveniente con la razón y que hacen que la acción sea buena por el género, así como lo es el vestir al desnudo; y hay objetos que producen algo discordante con la razón, como tomar lo ajeno, y esto es hacer algo en su género malo. Y hay objetos que ni producen algo conveniente a la razón ni algo discordante con ella, como el hecho de coger una ramita del suelo o algo de este tipo. Y entonces se dice que estas acciones son indiferentes". "Pero si hablamos de la acción moral según el individuo, es necesario que cualquier acción moral particular sea buena o mala según alguna circunstancia. Pues no puede acontecer que se dé una acción singular sin circunstancias que la hagan recta o torcida. Pues si una cosa se da cuando es preciso y donde es preciso, etc., una acción tal es ordenada y buena; pero si alguna de estas cosas falla la acción será desordenada y mala. Y esto puede considerarse máximamente en la circunstancia de fin. Pues lo que se hace por una necesidad justa o por una utilidad piadosa, se hace honorablemente y la acción será buena". (De Aquino, T. 2001, art. V, in corp.).

Ahora bien, si las circunstancias son, como lo afirma Tomás de Aquino, análogas a los accidentes de la sustancia primera, esto es, determinantes con necesidad en las cosas singulares, entonces se confirma que toda acción examinada en su concreción es siempre susceptible de una valoración ética, positiva o negativa.

Lo cual lleva el estudio de la experiencia moral a una situación privilegiada respecto de otros saberes teóricos. Pues, mientras que la sustancia primera en tanto individuo (tode $t i$ ) resulta incognoscible para la ciencia demostrativa, al menos en la visión aristotélica (Aristóteles 1990, VI, 2); por su parte, la individuación del significado, el conocimiento o valoración de lo específico de la acción es posible solo en vistas de las circunstancias, transformándose éstas en el requisito teórico crucial si queremos comprender más de cerca la vida en su concreto acontecer.

'praepropere, laute, nimis, ardenter, studiose (con mucha celeridad, espléndidamente, en exceso, ardientemente, con ahínco). (Tomás de Aquino, 2000: Art. VI in corpore). 
Tal diferencia nos mueve, entonces, a tratar la ética y su aprehensión esencial de lo circunstancial y contingente más como sabiduría que como saber fundado en principios generales o universales, empíricos o apriorísticos.

Debemos subrayar esto: que, para nuestros propósitos, la interacción es el modo privilegiado de la acción, puesto que es precisamente en este ámbito en el que ocurre la experiencia moral y su continuo proceso de autoevaluaciones y conflictos.

La pregunta que ahora intentaremos contestar es en cuáles condiciones debe advenir la comunicación humana para que pueda llamarse 'buena' por quienes la realizan y experimentan.

La acción comunicativa debe ser experimentada como un encuentro determinado en el mundo de los sujetos interactuantes, encuentro que resguarde su integridad y su iniciativa como sujetos. A este principio lo llamaremos 'principio de reciprocidad'. Esta condición de sujetos que convergen cada uno desde sí, hace que la acción sea en sí misma evaluable por su significado compartido, por el modo de convergencia que éste implica. No obstante, el valor de dicha acción es siempre susceptible de volverse conflictivo por ser rehén de la circunstancia.

En conclusión, en el estudio de la acción en general entra un elemento que no es esencial a la definición de su significado: la instancia del sentido. Ahora, cuando nos acercamos a la interacción comunicativa, la relación entre significado y sentido va a hacerse aún más compleja: pues ocurre aquí un hecho curioso: no siendo el sentido de la acción constitutivo de la comprensión intelectual de lo que un sujeto hace y expresa abiertamente al comunicarse con otro, tratándose de sujetos concretos es siempre posible que lo que uno manifiesta y significa para otro sea el modo por el que el manifestante oculta el verdadero sentido de su acción.

Es entonces en la comunicación, como permanente transferencia de mundo, donde el individuo, que de una y otra manera pretende vivir en la verdad, queda expuesto constantemente al falso testimonio y a la eventual no veracidad de los otros y al riesgo de su propia insinceridad. Pues en la experiencia moral no se juega tanto la verdad de las cosas sino la veracidad del vínculo interhumano. Paradójicamente, la experiencia ética no comienza sino este fracaso de la reciprocidad comunicativa.

\section{Referencias bibliográficas}

Aristóteles (1988), Categorías. Traducción y edición bilingüe de Giannini y Flisfisch, Santiago: Editorial Universitaria. Roma.

(1988), Etica Nicomachea, Classici Bur, Rizzoli, edizione bilingue, (1990), Metafísica. Madrid: Editorial Gredos, edición trilingüe.

Castelli, E. (1965), Lo Demoniaco en el Arte. Santiago: Editorial Universitaria. 
Cassiano, I. (1965), Institutions cénobitiques. Trad. francesa en Les éditions de Cerf, Paris.

De Aquino, T. (1986), De Veritate. Traducción, prefacio y notas de Humberto Giannini y Óscar Velásquez. Santiago: Editorial Universitaria.

(2001), Cuestiones Disputadas: Acerca de lo Malo. Edición bilingüe de Giannini y Flisfisch, Consejo Superior de Investigaciones Científicas, Madrid.

Giannini, H. (2008), La Metafísica eres Tú. Santiago: Editorial Catalonia.

Gide, A. (1914), Los sótanos del Vaticano. Madrid: Ediciones Argonauta.

Ricoeur, P. (1986), La semantica dell'azione. Roma: Ed. Jaca Book.

(1963), "Symbolique et temporalité", Archivio di Filosofia, Roma. 